\title{
FABRICAR OU IMPORTAR? EIS A QUESTÃO. O CASO DA INDÚSTRIA SPINBRAS
}

\section{MANUFACTURE OR IMPORT? HERE IS THE QUESTION. THE SPINBRAS INDUSTRY CASE}

\author{
Recebido em 31.10.2017. Aprovado em 16.11.2018 \\ Avaliado pelo sistema double blind review \\ DOI: http://dx.doi.org/10.12712/rpca.v12i4.12486
}

\author{
Arildo Ferreira \\ arildo@unicentro.br \\ Universidade do Vale do Itajaí (UNIVALI), Itajaí/SC, BRASIL \\ ORCID: https://orcid.org/0000-0002-8893-4099
}

\section{Rossano Linassi}

rossano.linassi@ifc.edu.br

Universidade do Vale do Itajaí (UNIVALI), Itajaí/SC, BRASIL

ORCID: https://orcid.org/0000-0002-9078-5344

\author{
Anete Alberton \\ anete@univali.br \\ Universidade do Vale do Itajaí (UNIVALI), Itajaí/SC, BRASIL \\ ORCID: https://orcid.org/0000-0002-6477-0122
}

\begin{abstract}
Resumo
O presente caso para ensino procura apresentar o dilema vivenciado por uma empresa do setor de metalurgia, a Spinbras, fabricante de peças para motosserras, entre continuar com sua produção ou terceirizar suas atividades. O caso relata a trajetória da empresa, desde o começo difícil em 1975, até os dias atuais em que se tornou referência tecnológica em seu setor de atuação. Irineu, um dos gestores, tem quebrado a cabeça para decidir o futuro da empresa, já que recebeu uma tentadora proposta de um parceiro chinês, que a um custo menor, se propõe a fabricar na China os produtos da Spinbras, com o mesmo padrão de qualidade. Nesse caso, a Spinbras importaria esses produtos para serem entregues aos seus clientes. Irineu, por um lado, tem pensado nas dificuldades que encontra no Brasil para manter as atividades da empresa, como a burocracia e altos encargos trabalhistas. Por outro lado, avalia o impacto social que será causado pela demissão de seus mais de cinquenta funcionários. Importar da China ou continuar fabricando, busca uma reflexão sobre os diversos temas que permeiam este caso, levando o aluno a assumir o papel de Irineu enquanto gestor, em algumas decisões chaves, como: analisar os ambientes externo e interno da empresa, buscando forças e fraquezas, oportunidades e ameaças; analisar as questões que envolvem a responsabilidade social corporativa; analisar as vantagens e desvantagens de importação da China. A utilização deste caso é indicada para cursos de administração na graduação e pós-graduação.
\end{abstract}

Palavras-chave: Responsabilidade Social. Importação. Ambiente Empresarial.

\begin{abstract}
This teaching case presents the dilemma experienced by a company in the metallurgy sector, Spinbras, a manufacturer of parts for chainsaws, between continuing its production or outsourcing its activities. The case reports the trajectory of the company, from the difficult beginning in 1975, to the present day when it became technological reference in its sector of activity. Irineu, one of the managers, has broken his mind to decide the future of the company, as he received a tempting proposal from a Chinese partner, who at a lower cost, intends to manufacture in China the products of Spinbras, with the same standard of quality. In that case, Spinbras would import these products to be delivered to its customers. Irineu, on the one hand, has been thinking about the difficulties he faces in Brazil to maintain the company's activities, such as bureaucracy and high labor costs. On the other hand, it assesses the social impact that will be caused by the dismissal of its more than fifty employees. Importing from China or continuing to manufacture, it seeks a reflection on the various themes that permeate this case, leading the student to assume the role of Irenaeus as a manager, in some key decisions, such as: analyzing the external and internal environments of the company, seeking strengths and weaknesses, opportunities and threats; analyze issues involving corporate social responsibility; analyze the advantages and disadvantages of China's import. The use of this case is indicated for administration courses at undergraduate and graduate level.
\end{abstract}

Keywords: Social Responsibility. Import. Business Environment. 


\section{Introdução}

Em um típico dia de verão, no interior do Paraná, enquanto observava a movimentação na fábrica, com os empregados trabalhando a todo vapor, Irineu, que chegara recentemente de mais uma viagem à China, com duração de 40 dias, estava preocupado com o andamento dos negócios, em função da situação econômica atual, principalmente do Brasil, e também com o futuro de sua empresa. Durante a viagem Irineu manteve diversos contatos comerciais com empresários locais e de outras partes do mundo, em encontros particulares ou mesmo nas diversas feiras que participou. Em um desses encontros, Irineu recebeu uma proposta para deixar de produzir no Brasil sua linha de produtos para motosserras e importar de fábricas chinesas essa produção, com custo menor, maior lucratividade e garantia de qualidade. Com base nessa proposta, Irineu encomendou um estudo para descobrir qual o posicionamento correto para sua empresa diante do atual cenário competitivo, e da possibilidade de mudança da produção para as fábricas chinesas.

Ao analisar o estudo, Irineu observou que os resultados apontavam que em função da globalização e facilidades de importação, seria mais viável economicamente, importar de fabricantes chineses os produtos do atual portfólio, com margens de lucros significativamente maiores, do que continuar produzindo e convivendo com diversas dificuldades, como a situação econômica desfavorável do Brasil, a concorrência desleal, os problemas logísticos e a falta de mão de obra especializada. Optando pela continuidade da produção no Brasil, manteria o nível de empregos, continuaria buscando novos mercados, mas abriria mão de elevar seus lucros. Se optasse pela importação, poderia manter sua carteira de clientes, no Brasil e na América do Sul (os quais, possivelmente nem perceberiam que o produto agora era importado), mas teria que fechar a sua produção, o que poderia acarretar diversos problemas.

Irineu não parava de imaginar as consequências dessa troca de função, de fabricante para importador. Por um lado, lucros maiores poderiam garantir mais qualidade de vida para si, os sócios e seus familiares, mas por outro lado, lhe incomodava o fato de ter que fechar a fábrica, demitir mais de 50 funcionários, alguns com mais de 35 anos de serviço e a maioria com mais de oito anos trabalhados na empresa. Se isso realmente ocorrer, sabe que estará contribuindo para o agravamento do quadro social no Brasil, no qual se tem registrado aumento constante no nível de desemprego, conforme observado na Figura 1. De acordo com Silveira e Cavallini (2017) e Instituto Brasileiro de Geografia e Estatística (IBGE), por meio da pesquisa Pnad Contínua, o desemprego tem subido constantemente desde 2012. De janeiro a março de 2017, a taxa de desemprego no Brasil chegou a 13,7\%, atingindo uma população de 14,2 milhões de pessoas.

Figura 1 . Perspectiva de Desemprego no Brasil

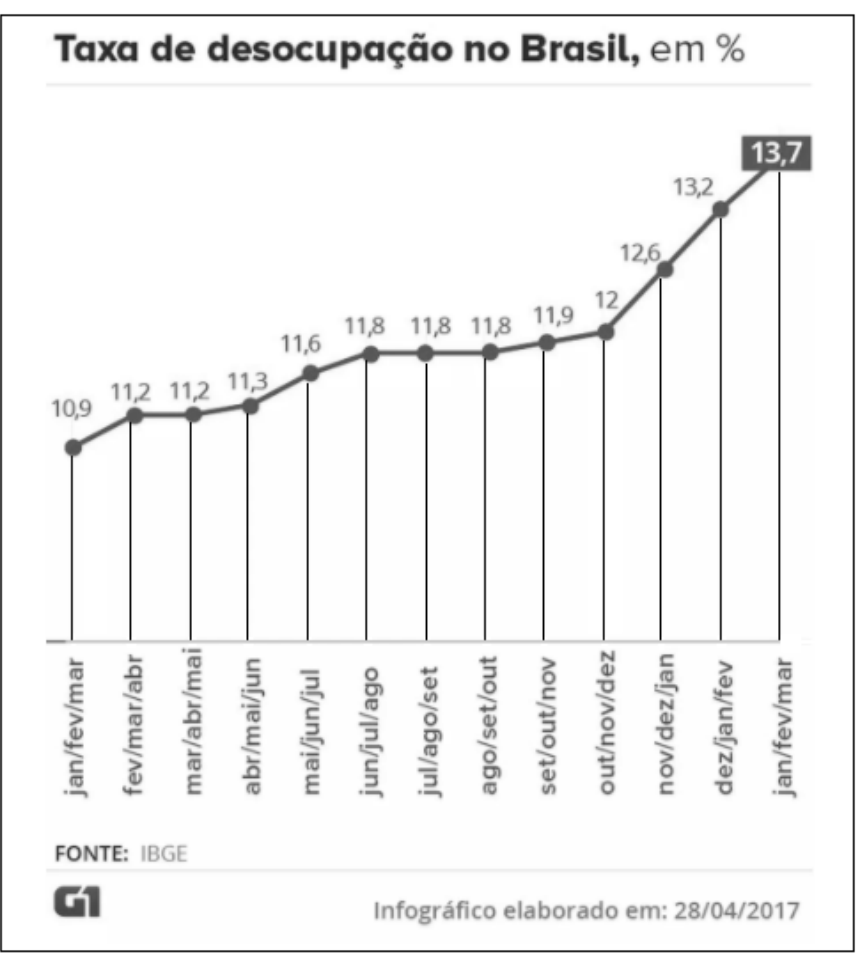

Fonte: SILVEIRA, CAVALLINI (2017), IBGE (2017)

\section{Histórico da Metalúrgica Spinbras}

Em meados da década de 1970, a família do Sr. João Avilar, imigrante italiano, mudou-se da cidade de Palmas-PR, para Guarapuava-PR, em busca de melhores oportunidades de emprego. A família era composta pelo patriarca, Sr. João, sua esposa Amélia e seus três filhos, Henrique, Celina e o mais novo Irineu. Assim que chegaram a Guarapuava, Seu João conseguiu emprego em uma oficina mecânica, onde também empregou como ajudantes os seus dois filhos homens. Alguns meses depois, começou a trabalhar por conta própria quando juntos com os dois filhos, alugaram uma oficina mecânica, desenvolvendo atividades de consertos de carros. 
$\mathrm{Na}$ oficina faziam diversos serviços, mas eram especializados em arrumar e regular carburadores, visando principalmente à economia de combustível (haja vista que a função do carburador, consiste em promover a combinação adequada de ar e combustível para que ocorra a e movimentação do veículo). Vale lembrar que nessa época todos os veículos automotores funcionavam com carburadores e que a injeção eletrônica de combustíveis somente dominou o mercado a partir de 1991. Em 1994 a produção de carburadores foi encerrada no Brasil.

Após dois anos de trabalho na oficina, para surpresa geral, o proprietário do imóvel, avisou-os que havia vendido o local e que deveriam encerrar imediatamente o contrato de aluguel. Foi um balde de água fria em todas as pretensões da família, o desemprego não somente bateu à porta, como se abrigou na casa da família Avilar. Sem desanimar, Seu João, com o conhecimento sobre o funcionamento dos carburadores e os problemas que ocorriam (principalmente pela falta ou excesso de combustível nos mesmos), desenvolveu um equipamento elétrico ligado ao giclê do carburador, fazendo com que o combustível fosse utilizado na medida exata, tornando o veículo mais eficiente.

Com o novo invento, Seu João e seus dois filhos começaram a vender o produto no varejo "de carro em carro". Todo tempo disponível era usado para produzir e vender o dispositivo. Essa atividade foi a responsável por custear as despesas da família nos anos seguintes.

\section{Novo ramo - 0 início da fundição}

Outra forma de ganhar a vida foi alcançada quando Seu João e os filhos desenvolveram uma forma para fabricar terminais de contato de baterias de automóveis, a partir do derretimento de chumbo. No início tudo era muito precário, o chumbo era derretido em uma panela de ferro grande, com fogo em um buraco nos fundos do mesmo terreno que abrigava a residência da família. As peças também eram vendidas no varejo. Certo dia, um cliente dos terminais, e que também revendia peças para motosserras, vendo que os terminais ficavam bem feitos, indagou o Seu João se ele seria capaz de produzir uma determinada peça de motosserra, em alumínio, dando a ele um modelo para que as peças fossem reproduzidas. Deveriam ser feitas 100 unidades. Seu João e seus filhos desenvolveram um molde da peça, e mesmo sem conhecimentos mínimos de química, como ponto de fusão dos metais, e apesar de vários outros problemas, produziram as peças de forma muito semelhante ao modelo. $\mathrm{Na}$ entrega das peças as duas partes ficaram surpresas. O comerciante que encomendou as peças, pela semelhança do produto ora apresentado, com o original, e Seu João quando foi pago com um valor cinco vezes maior do que esperava pela produção. Imediatamente um novo pedido com outros tipos de peças foi feito para o Seu João. Começava aí a atividade de metalurgia.

Para dar início à fabricação dos novos produtos, alguns equipamentos foram comprados em ferrosvelhos e outros foram desenvolvidos, mesmo que rusticamente, como um forno de fundição e um torno. Algumas visitas em metalúrgicas foram realizadas, além de muitos estudos sobre o processo de fundição de metais. Até esse momento os dois filhos do Seu João, Henrique e Irineu, sempre acompanharam as decisões do pai e participaram diretamente de tudo o que acontecera até então. Seu João, ao ver a possibilidade de crescimento nesse ramo, determinou novas funções para os filhos: Henrique deveria fazer os moldes e cuidar da produção; Irineu deveria cuidar da parte burocrática, dos novos contatos e da pesquisa de produtos. Na mesma medida em que aumentaram a qualidade de seus produtos, aumentaram também os novos pedidos de comerciantes de cidades próximas. Nesse momento foram contratados os dois primeiros empregados.

Na década de 1990, a empresa já contava com uma diversidade de produtos, empregava diretamente dez funcionários e vendia seus produtos em várias partes do estado do Paraná. Em 1998, adquiriram da Prefeitura, um novo terreno no Distrito Industrial, com cerca de $8.000 \mathrm{~m}^{2}$, onde, com recursos próprios, construíram a nova sede com mais de $2000 \mathrm{~m}^{2}$, com espaços distintos para modelagem, usinagem, cromagem, acabamento, estoques, além de espaço para funcionários, como refeitório e área de lazer.

Também nessa época, os negócios já eram administrados inteiramente pelos dois filhos. Irineu, o mais novo, ficou responsável pela gerencia comercial e industrial e novos projetos, Henrique por sua vez, ficou com o papel de criar os moldes para fabricação dos novos modelos de produtos desenvolvidos pela empresa, além de acompanhar o irmão nas decisões. O Patriarca já com idade avançada e aposentado, ainda tinha alguma participação, principalmente auxiliando os filhos na condução dos negócios de maneira 
geral. Irineu, sentindo necessidade de conhecimentos técnicos mais profundos para utilizar no negócio, entrou na universidade e cursou Administração de Empresas, sendo considerado pelo corpo docente da Universidade, um dos melhores acadêmicos que até então frequentaram o curso.

\section{O Paraná não foi o limite - situação atual da empresa}

Seu João (in memorian) com certeza estaria orgulhoso de saber onde seus filhos chegaram, depois de anos de muitas dificuldades. O seu "panelão" com chumbo derretido foi só o início da criação de uma empresa atualmente muito respeitada no setor de metalurgia, tanto no Brasil quanto em algumas partes do mundo. Atualmente, a Spinbras possui uma linha com mais de 30 produtos, fundidos em diversos tipos de materiais, como alumínio, ferro e polietileno, os quais são vendidos para todo o Brasil e América do Sul, através de representantes. A qualidade de seus produtos é reconhecida internacionalmente, tanto que uma das maiores empresas do ramo de motosserras do mundo, com sede na Itália, propôs para que a Spinbras produzisse exclusivamente para ela, com um contrato longo e bem remunerado, todavia esta opção foi rejeitada pelos diretores, pois de certa forma, limitaria muito seu eventual retorno ao mercado nacional. A empresa emprega hoje, diretamente, 50 pessoas em sua fábrica, provida com equipamentos de altíssima tecnologia produzidos no Brasil, Europa e no Japão.

Irineu, buscando solucionar seu dilema e sempre consciente e atualizado lembra-se de uma matéria que leu no Jornal Estado de São Paulo, apontando o Brasil como o maior pagador de encargos trabalhistas do mundo (Figura 2) o fazendo pensar nas diversas implicações que sua decisão teria para sua indústria, na sua vida e na de seus funcionários.
Figura 2 . Encargos Trabalhistas no Brasil

\section{Brasil lidera ranking de encargos trabalhistas}

GULLHERUIE WALTENBERG, DAAGÉNCIA ESTADO

Aqui, paga-se em média $57,56 \%$ do valor bruto do salário em tributos, enquanto a média global é de $22,52 \%$

O Brasil é o País com os encargos trabalhistas mais elevados em um grupo de 25 nações analisadas pela rede mundial de auditoria e contabilidade UHY. Nesse grupo, que inclui o G7 - grupo dos sete países mais industrializados - e os Brics principais economias emergentes -, o Brasil desponta como líder mundial ao pagar, em média, $57,56 \%$ do valor bruto do salário em tributos. A média global é de $22,52 \%$.

Esse volume de tributos significa dizer que, ao pagar um salário anual bruto de US 30 mil, o empresário brasileiro paga US\$ 17,267 mil adicionais de contribuições trabalhistas, incluindo todos os custos empregatícios mandatórios como coberturas de saúde e provisões de pensões. A média mundial implica em US\$ 6,757 mil extras, menos da metade do que é pago no Brasil.

Fonte: Jornal Estado de São Paulo (2013)

Apesar de hoje a empresa gozar de respeito no mercado, encontra inúmeras dificuldades para manter seus negócios de forma competitiva, principalmente atrelados aos altos custos de investimentos, de impostos, de mão de obra, nesse caso também com dificuldades de contratações. Outra dificuldade diz respeito a diversos produtos fabricados na China, entrando no Brasil com preços menores que os praticados aqui, muitas vezes, com qualidade igual ou até mesmo superior aos produtos nacionais.

Diante do crescimento amplo dos negócios, e visando novos horizontes, Irineu começou a acompanhar o desenvolvimento dos mercados internacionais, com interesse em conhecer o mercado Chinês, começou a viajar anualmente para a China em a partir de 2008, onde conquistou inúmeras amizades que se estendem além dos negócios. $\mathrm{Na}$ China, encontrou parceiros que poderiam produzir as peças que a Spinbras fabrica, nas mesmas condições de qualidade. Essa medida vem sendo tomada por inúmeras empresas do mundo, principalmente de eletrodomésticos, que terceirizam a fabricação de diversos componentes, principalmente motores, em fábricas da China. Em matéria do Jornal O Povo (2014) o agente de carga internacional da CTI Cargo, Bruno Toscano, estima que $70 \%$ das importações são oriundas da China. "Trazemos de tudo: alimento, indústria têxtil, construção civil, eletroeletrônicos. Ninguém consegue chegar perto deles". Desta forma é importante discutir as 
possibilidades de acordo com o mercado atual e ainda levar em consideração todos os valores envolvidos, além da documentação e da contratação de empresas especializadas em comercio exterior.

Com as informações fervilhando em seus pensamentos Irineu foi ao encontro de um amigo, Edson, que trabalha com comércio exterior para tentar descobrir os passos básicos para importar da China, buscando fechar as lacunas que ainda restam para sua tomada de decisão.

- Tudo bem Edson? Gostaria muito que você me explicasse como funciona a importação de produtos da China e quais os passos básicos para quem quer iniciar neste negócio?

- Meu amigo, para começar todo processo, visto que você já tem os contatos na China, você terá de contratar uma trade. As trades são empresas que possuem autorização para importar, chamada Radar, e repassam os produtos. É ela também que irá providenciar o Radar da sua empresa, uma autorização para importar emitida pela Receita Federal. A permissão é dividida em limitada ou modalidade simplificada (até US\$ 150 mil por semestre) e ilimitada ou modalidade ordinária (acima de US\$ 150 mil por semestre), neste ponto teríamos de avaliar a melhor opção para o seu caso.

- Certo, mas com isso tenho tudo pronto para começar a importar? Me parece fácil demais...

- Bom, não é tão fácil assim. Você vai precisar ainda de um despachante aduaneiro que cuidará da nacionalização e liberação da carga no porto e do cálculo dos impostos. Normalmente este profissional cobra, em média, 2 a 3 salários mínimos por processo.

- Entendo. E quais os demais custos envolvidos nestas transações?

- O gerenciamento do processo custa em média de 5 a $6 \%$ do valor do pedido. O frete custa US\$ 1.700 por container de 20 pés (28 toneladas), o menor, e não é obrigatório comprar um container completo. Ainda é preciso pagar 30\% para produzir e 70\% para embarcar. A China não tem estoque.

- Ok, você pode me explicar melhor esta questão dos $30 / 70$ ?

- Ao receber os 30\% do valor total é dado o início da produção dos materiais que você quer importar. Do pedido à chegada são aproximadamente 90 dias, dependendo de cada produto e suas especificações técnicas e exigências legais para a entrada no Brasil, o que no seu caso não será um grande problema. Após aprovado o pagamento final $(70 \%)$, o despachante aduaneiro informa ao agente de cargas para retirála no porto. É sempre válido documentar todos os processos.

\section{- E quanto ao seguro da carga?}

- O seguro da carga é outra questão a ser considerada, custa $0,26 \%$ do valor e cobre roubo e danos à carga. Temos que pensar ainda no transporte e em qual porto será mais vantajoso atracarmos com sua mercadoria, pois tudo isso dependerá o valor final de sua carga.

- Muito obrigado Edson suas informações serão de grande valia no meu processo de decisão. Por sorte as questões como dominar o idioma e a cultura local, que são algumas das dificuldades na negociação, já foram superadas por mim através das minhas viagens.

- Eu que agradeço, logo te enviarei um e-mail com um resumo de tudo que conversamos. Vou te mandar também o endereço de um portal explicativo (figura 3) para as transações.

Figura 3 . Portal Câmara Brasil China

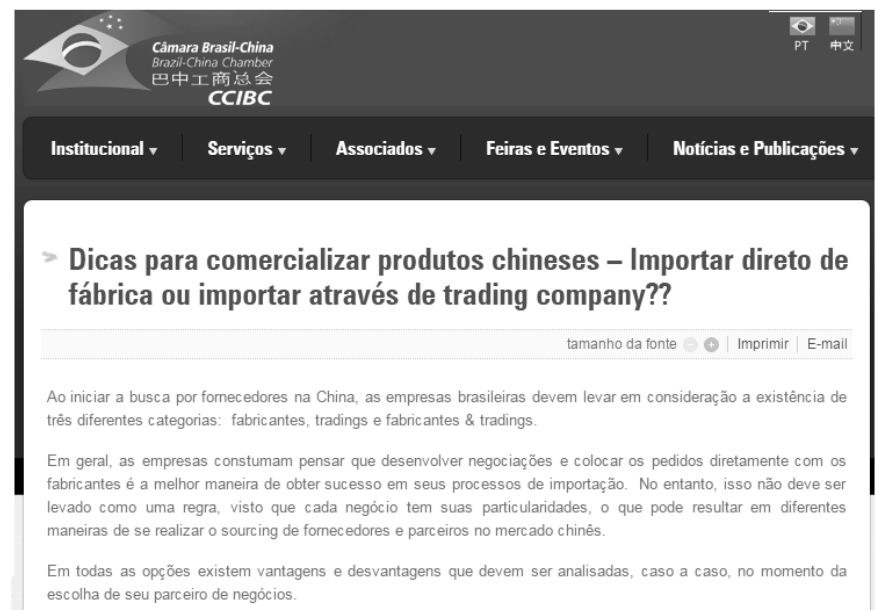

Fonte: Portal Brasil China (2015)

Um estudo realizado por uma empresa de consultoria, em 2015, considerando todas as questões legais, apontou que se a empresa Spinbras importasse da China todos os seus produtos, compraria cada item com custo significativamente menor que os atuais em sua fábrica. Considerando que continuaria atendendo normalmente os seus clientes, com os mesmos quesitos de qualidade, quantidade e tempo de entrega, teria automaticamente aumento nos lucros e eliminaria 
todos os problemas enfrentados pela gestão de qualquer tipo de empresa. Nesse caso, simplesmente poderia vender todos os equipamentos que possui, dispensar a maioria dos empregados, e utilizar o mesmo barracão como um centro de distribuição das peças que chegariam da China. Mas isso tudo traz à memória de Irineu, a última festa natalina realizada para os colaboradores da empresa e seus familiares, na qual compareceram mais de 250 pessoas.

Irineu continua se questionando e buscando o máximo de informações (Figura 4) para tomar a melhor decisão, pois de um lado o Brasil está firmando parcerias importantes com a China e diversos investimentos serão feitos aqui, o que fortalecerá ainda mais os acordos e o comércio entre os dois países, de outro lado, vê as instabilidades econômicas e financeiras como algo que deve ser observado com cautela, principalmente o desaquecimento do setor industrial e a flutuação e alta do dólar, o que poderia gerar custos não previstos neste processo.

Figura 4 . Informações sobre comércio Brasil China

\section{Brasil e China assinam 35 acordos em visita do premiê ao País}

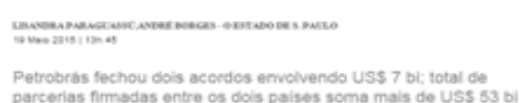

mercado

Instabilidade do dólar inibe

importações e paralisa empresas

\section{mercado \\ Brasil e China confirmam acordos de mais de US $\$ 33$ bi e ajuda à Petrobras}

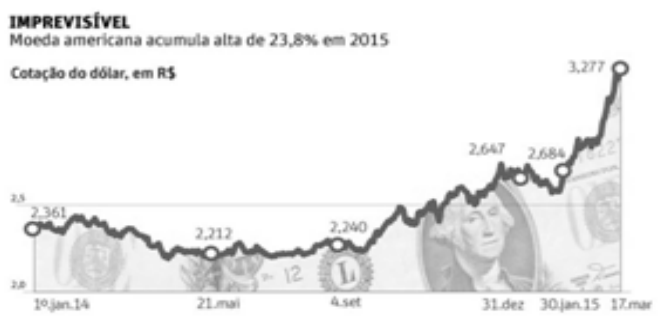

Fonte: Jornal Estado de São Paulo, 19/05/2015

Além de tantas incertezas econômicas, Irineu se preocupa também com o futuro dos funcionários, alguns deles estão na empresa há muito tempo, há relações de amizade entre eles. Irineu sabe, porém, que para o bem dos objetivos da empresa precisa tomar uma decisão, e não pode demorar muito para isso. Por um lado, Irineu sabe da responsabilidade com os funcionários e suas famílias. Se importar os produtos, certamente terá que demitir boa parte dos funcionários, por outro lado vê uma oportunidade de aumentar seu grau de competitividade e de ampliação dos negócios. Afinal, qual a melhor decisão para ser tomada: importar os mesmos produtos aqui fabricados, ou manter a estrutura atual preservando os empregos e contribuindo socialmente com o País?

\section{Notas de ensino}

A aplicação do caso prevê leitura previa dos participantes estimulando a formação de grupos de discussão para em seguida solicitar que sejam formados dois grupos opositores. Um defendendo a importação da China e o outro a posição de continuidade da fábrica, apresentando de forma oral, a sua análise a respeito do caso, defendendo seus pontos de vista e apontando as razões que sustentam sua escolha. O professor deve realizar o fechamento do caso considerando as opiniões manifestadas pelos alunos e fazer o mapa conceitual, analisando as alternativas à luz da teoria. 


\section{Fonte de Dados}

Este caso foi elaborado a partir de dados reais, coletados através de entrevista presencial com um dos principais personagens, e com o analista de comércio exterior em abril de 2015. É baseado em fatos reais e os nomes dos personagens são fictícios.

\section{Objetivos de Aprendizagem}

O presente caso pode ser aplicado em cursos de Administração, com alunos de graduação e PósGraduação. A partir do caso, pode-se desenvolver vários estudos, principalmente nas áreas de empreendedorismo, comércio exterior, verticalização versus horizontalização, administração da produção e gestão em empresas familiares. As informações têm como objetivo educacional discutir o planejamento e a gestão estratégica.

\section{Aplicação do caso}

Com o propósito de cumprir os objetivos de ensino propostos, sugere-se que os professores adotem os seguintes passos para aplicação deste caso de ensino:

a) Propor aos alunos que, individualmente, façam a leitura prévia do caso de ensino; ou destinar em torno de 20 minutos durante a aula;

b) Estimular que, em pequenos grupos, de 3 a 4 pessoas, os alunos debatam e discutam sobre a situação-problema descrita no caso e procurem analisar e examinar hipóteses e proposições para a solução do mesmo; (20 minutos).

c) Em seguida, dispor a turma em círculo e solicitar que cada grupo apresente, de forma oral, a sua análise a respeito do caso e a possibilidade que julgue mais conveniente para a solução dos problemas enfrentados, fazendo um pequeno resumo no quadro para melhor visualização; minutos para cada grupo).

d) Realizar o fechamento do caso, revelando a decisão de fato tomada pelo Irineu sobre o dilema apresentado.

Cabe salientar, ainda, que o professor ao distribuir o caso para os alunos, deverá suprimir a parte do fechamento do caso. Também não é interessante fornecer uma resposta definitiva para a solução do caso, pois o objetivo é que o professor faça uma mediação das análises de todas as propostas apresentadas para solução do conflito, ponderando, juntamente com os alunos, as vantagens e desvantagens de cada escolha.

\section{Questões para discussão}

1. Como você descreve o ambiente de negócios da SpinBras e quais as principais oportunidades e ameaças, forças e fraquezas nos possíveis cenários apresentados.

2. Dado o contexto atual econômico e político do Brasil e da China, qual a melhor estratégia a ser adotada por Irineu.

3. A empresa deve buscar a maior lucratividade, deixando as questões sociais em segundo plano? Ou ao contrário, deve priorizar as questões sociais, mesmo que isso acarrete menores lucros. Justifique sua resposta.

4. Como as dimensões de oportunidade, empreendedorismo e inovação foram trabalhadas pela família ao longo da historia da SpinBras.

5. Em termos de oportunidades de mercados, a importação pode ser considerada? Qual a estratégia adotada por você para a importação de peças e suspensão das atividades industriais no Brasil.

6. Baseado na experiência de viagens de Irineu, no cenário apresentado e pensando como um empreendedor, qual a viabilidade de criação de uma nova empresa de importação, mesmo que a decisão seja manter a atual indústria. 


\section{Analise do caso e conexão das questões com a literatura}

A questão 1 possibilita a busca de repostas sobre a dinâmica de funcionamento de uma organização no ambiente geral de competitividade e suas interelações com as variáveis existentes. A gestão de organizações requer amplo conhecimento por parte dos gestores, de todos os componentes do ambiente que caracterizam a existência da empresa, tanto no aspecto externo quanto interno (WRIGHT, KROLL, PARNELL, 2009). No ambiente externo o gestor não tem controle sobre a fluência das variáveis, tendo em vista que normalmente são impostas pelas instancias políticas ou mesmo pelos concorrentes. Apesar disso, deve estar atento aos acontecimentos para que possa prever possíveis mudanças e assim tomar com antecedência, as decisões, tanto para aproveitar alguma oportunidade ou mesmo para minimizar os impactos negativos de alguma ameaça (MINTZBERG, 2001). Nesse caso, o Professor poderá realizar ampla discussão com os alunos com a apresentação de situações que ocorrem na atualidade, como por exemplo, os efeitos da inflação nos preços e nas preferências de compras dos consumidores.

Já no ambiente interno o controle fica mais próximo do próprio gestor, pois as decisões que afetam os componentes desse ambiente, como níveis de produção, políticas de marketing, estratégias de vendas, planejamento de recursos humanos, decisões financeiras para investimentos em maquinários, além de outras, embora tenham ampla relação com o ambiente externo (KOTLER, KELLER, 2006), dependem diretamente das percepções do gestor e da sua equipe.

Nas duas situações apresentadas, o Professor poderá utilizar como ferramenta análise de ambientes, a análise SWOT, utilizada para monitorar tanto o ambiente interno quanto o externo da empresa. Essa análise consiste em diagnosticar as partes interna e externa da empresa visando à identificação das forças (strengths), fraquezas (weaknesses), oportunidade (opportunities) e ameaças (threats), além de identificação de pontos fortes e pontos a melhorar. As quatro zonas da matriz SWOT servem como indicadores da situação da organização. A análise SWOT serve para posicionar ou verificar a situação e a posição estratégica da empresa no ambiente em que atua (MCCREADIE, 2008).

A identificação do ambiente interno e externo revela-se muito útil para estabelecer estratégias e definir prioridades próprias de seu mercado de atuação para orientar os rumos das decisões da empresa. Também para decidir qual a escolha a ser tomada de forma a atingir os objetivos, tendo sempre um olhar crítico sobre as ameaças. Discutindo os pontos fortes, pontos fracos, oportunidades e ameaças da empresa, nos dois cenários propostos: 1) manter a produção nacional ou 2) importar diretamente da China. A figura 5 apresenta a Matriz SWOT da empresa Spinbras.

Figura 5 . Matriz de Análise SWOT da Spinbras
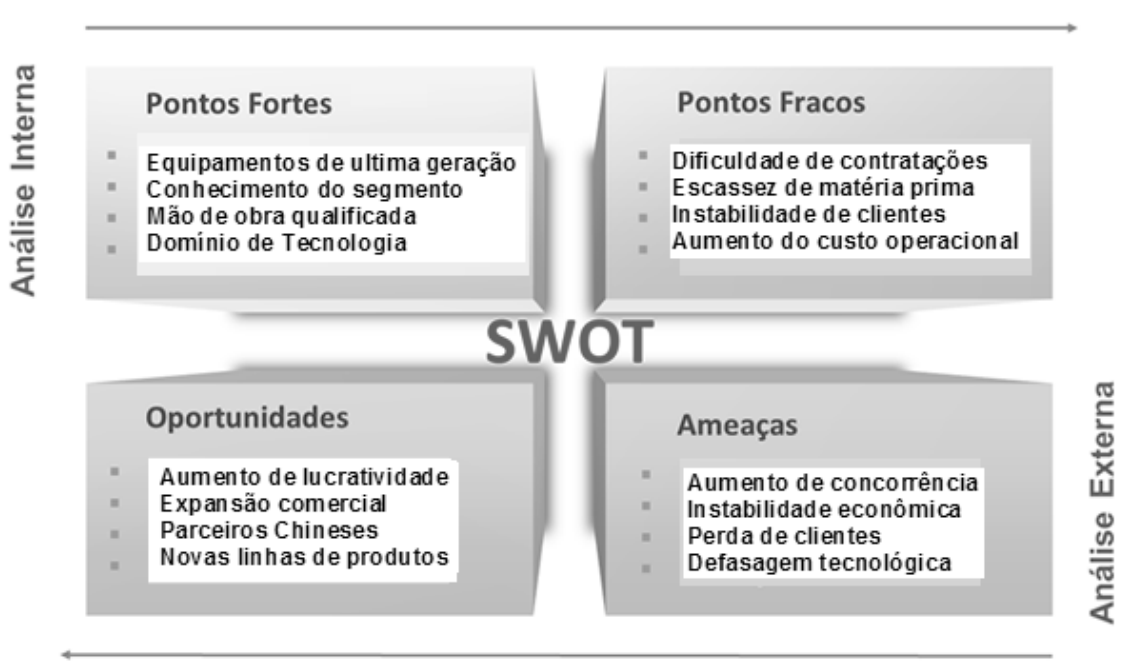

Fonte: Elaborado pelos Autores (2015) 
Para Oliveira (2007) o conceito básico de estratégia está relacionado à ligação da empresa ao seu ambiente. E, nessa situação, a empresa procura definir e operacionalizar estratégias que maximizem os resultados da interação estabelecida. Tomar uma decisão sobre qual o melhor caminho a ser trilhado para a consecução de seus objetivos. Consoante com as ideias de Porter (1998), empresas que querem ganhar vantagem competitiva devem fazer uma escolha entre as opções, uma vez que "ser tudo para todas as pessoas" é uma receita para mediocridade estratégica e desempenho abaixo da média (PORTER, 1998).

A estrutura de Porter de estratégias genéricas poderia ser utilizada, uma vez que constituem estratégias para diferenciar a principal área de negócios. Segundo Mintzberg e Quinn (2001), Porter acredita que há dois tipos básicos de vantagem competitiva que uma empresa pode possuir: custos baixos ou diferenciação. Isso combina com o escopo de operação de uma empresa a fim de produzir três estratégias genéricas para atingir desempenho acima da média em um setor: liderança de custo, diferenciação e foco. Uma organização pode elaborar seus negócios de várias formas. Pode desenvolver suas ofertas de produtos dentro de determinada área de negócios, pode desenvolver seu mercado via novos segmentos, novos canais ou novas áreas geográficas, ou pode simplesmente empurrar mais vigorosamente os mesmos produtos para os mesmos mercados. Isto está de acordo com Ansoff (1993) que propôs um modelo de quatro estratégias que se tornaria muito conhecido penetração de mercado, desenvolvimento de produto, desenvolvimento de mercado e diversificação.

A SpinBras realiza planejamento estratégico e está ciente de suas forças internas e externas, o que a coloca em situação de vantagem frente a seus competidores, visto que a empresa além de 40 anos de atuação, continua evoluindo e estudando o mercado em que esta inserida, buscando se adequar ao atual cenário econômico e político de crise, dificuldade de contratação de mão de obra especializada e alta no preço de matérias primas. Busca, ainda, através do uso da tecnologia e no desenvolvimento de novos produtos, oportunidades em seu mercado de atuação e expansão comercial.

\section{Novos mercados}

Outro ponto importante diz respeito ao tipo de crescimento que a empresa deve empreender. Essa situação está visível na questão 2. Nesse sentido, os alunos poderão ser estimulados a entender as estratégias de crescimento de Brasil e China e as formas de relacionamento político e comercial desses países. Como relatado no caso, a empresa Spinbras, através de seu Gestor Irineu, está buscando ampliar os seus negócios com empresários chineses, no entanto, antes de qualquer decisão, cabe ampla reflexão sobre a melhor maneira de ampliar essas relações. Existem diversos modelos de estratégia de crescimento empresarial: um dos mais utilizados é a matriz de Ansoff. Nesse modelo (Figura 6), o desenvolvimento da empresa é baseado em duas dimensões: os produtos que a organização oferece e os mercados que ela atinge. Por conta disso, o modelo também é chamado de matriz produtos-mercados (ANSOFF, 1990). A partir da combinação entre as dimensões, é possível identificar quatro tipos de crescimento: penetração de mercado (produtos atuais $\mathrm{x}$ mercados atuais); desenvolvimento de mercado (produtos atuais $\mathrm{x}$ mercados novos); desenvolvimento de produto (produtos novos $\mathrm{x}$ mercados atuais); e diversificação (produtos novos x mercados novos). Vale destacar que a partir de maio de 2015, Brasil e China assinaram 35 acordos comercias, em negócios que representam mais de R $\$ 150$ bilhões.

Figura 5 . Matriz de Ansoff

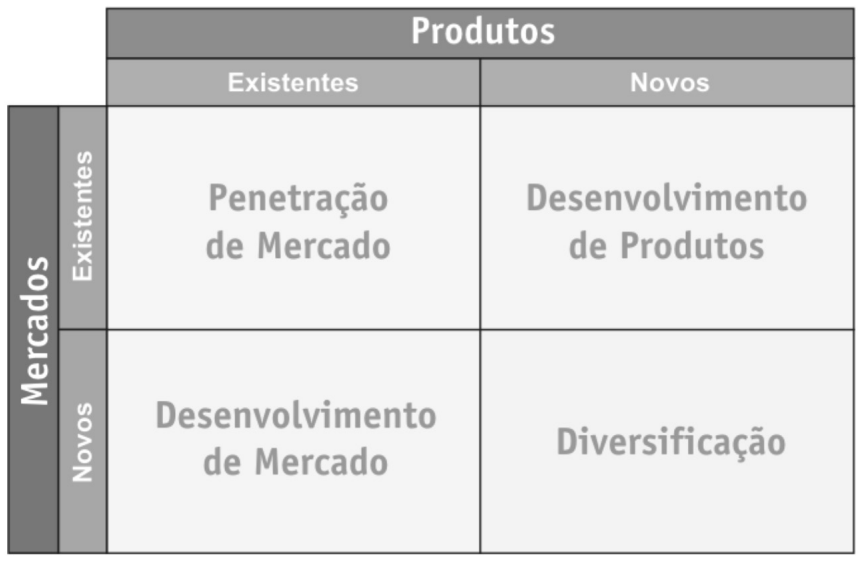

Fonte: Ansoff (1993)

Nesta questão os alunos poderão discutir qual a melhor estratégia de crescimento a ser adotada pela 
empresa, considerando que a mesma investe em tecnologia, utilizando máquinas e equipamentos de ultima geração provenientes da Europa e do Japão, possui contatos e parceiros em grandes empresas no Brasil e América latina para distribuição de seus produtos e ainda contatos comercias na China para possíveis importações.

\section{Responsabilidade Social Corporativa}

A responsabilidade Social Corporativa, contemplada na questão 3, possibilita a reflexão dos alunos sobre o papel da organização na sociedade. Normalmente as missões das empresas contemplam frases do tipo "servir adequadamente a sociedade", "atender com esmero e qualidade" e, "estar sempre a serviço dos interesses da comunidade". Assim pressupõe-se que as empresas não estão buscando somente o lucro, mas, além disso, tentam formas de se enquadrar aos interesses reais da sociedade que fazem parte, na qual criam mecanismos de interação, como fundações relacionadas a assuntos que afetam diretamente a vida das pessoas, tais como: cuidado de crianças abandonadas, cuidados com a natureza, incentivo à educação, saúde e cuidados aos idosos (TACHIZAWUA, 2008).

Grande parte do interesse das empresas em fazer parte das decisões da sociedade, se dá pelos aspectos da competitividade. Desde as últimas décadas, as empresas têm se deparado com mercado cada vez mais competitivo, em função de novas tecnologias que levaram ao aprimoramento da produção, além da crescente exigência de consumidores por produtos e serviços que atendam cada vez mais as suas necessidades. Assim, as empresas têm buscado se diferenciar umas das outras, no sentido de atrair para si a maior parcela possível de clientes (TENÓRIO, 2006). Entre as ferramentas de diferencial competitivo estão as ações de responsabilidade social empresarial, ou seja, essa função indica que as empresas assumam maiores compromissos diante da sociedade, ajudando a resolver problemas que são considerados de responsabilidade do estado, e com isso se afastando do viés que existem somente pela lucratividade.

As questões sobre responsabilidade social empresarial estão sendo discutidas desde o início do século XX (TENÓRIO, 2006), com o filantropismo, sendo esse conceito desenvolvido com a sociedade pósindustrial, para temas voltados ao voluntariado empresarial, cidadania corporativa, responsabilidade social corporativa e desenvolvimento sustentável. Com a transição da sociedade da economia agrícola para industrial, era responsável socialmente a empresa que considerava seus funcionários como parte do processo produtivo, e que eles poderiam ter algum tipo de direitos, além e tão somente do salário por produtividade comum à época. $\mathrm{O}$ desenvolvimento de tecnologias, aplicadas aos processos produtivos, ampliaram as discussões sobre o tema e afetaram drasticamente as relações de trabalho, ocasionando debates a respeito das obrigações empresariais para com seus funcionários.

As alterações nos modos de trabalho fizeram com que o trabalhador desenvolvesse maior produtividade com menos esforços físicos. Um exemplo clássico dessa situação pode ser reportado à Administração Científica, desenvolvida por Taylor, Ford e Fayol. Esse modelo basicamente dividia as atividades de um projeto em diversas tarefas, para as quais os funcionários eram treinados. $\mathrm{O}$ objetivo era eliminar a ociosidade e calcular os tempos e movimentos para cada atividade, podendo assim prever os níveis de produção padronizados. Essa prática, porem, recebeu forte resistência dos sindicatos dos trabalhadores, que não aceitavam o fato de receberem a mesma coisa para produzirem mais (SERTEK, 2006).

Logo após a década de 1950, o conceito de responsabilidade social ganha nova dimensão, passando a ser entendido como responsável socialmente a empresa que tem a capacidade de geração de lucros, criação de empregos, pagamentos de impostos e cumprimento das obrigações sociais e trabalhistas envolvendo os seus funcionários. A partir da década de 1970, com a percepção da exaustão dos recursos naturais, a responsabilidade social ganha nova obrigação, a de produzir sem comprometer o meio ambiente e a natureza. (TENÓRIO, 2006).

A partir de 1990, o interesse empresarial passa a ser em implementar o desenvolvimento de ações sociais, percebidas pela sociedade como um todo, na expectativa de que as atividades da organização refletirão diretamente na escolha dos consumidores por produtos que atendam toda gama de conceitos sobre as responsabilidades da empresa. Nesse período surgem diversas organizações não governamentais para o desenvolvimento do chamado terceiro setor. Também aparecem as fundações relacionadas a assuntos que afetam diretamente a vida das pessoas, como cuidado de crianças abandonadas, cuidados com a natureza, incentivo à educação, saúde e cuidados aos 
idosos, além de inúmeras outras (TACHIZAWUA, 2008).

Pelo lado das empresas, para Tachizawua (2008), essa estratégia pode ser vista como uma forma de se aproximar de forma simpática do consumidor, mostrando a ele que está interessada com os problemas sociais existentes, e que está disposta a ajudar encontrar soluções. Já pelo lado do consumidor, essa prática pode ser considerada como positiva na hora de suas compras de forma consciente no sentido de preservar as boas ações sociais que levam a melhorias da comunidade. Portanto, as atividades de responsabilidade social recebem também a dimensão de "ganha-ganha", resultando desse modo, melhoria no bem-estar e na qualidade de vida dos empregados, seus familiares e para comunidade.

No papel de Irineu, o discente poderá relacionar as implicações do fechamento da indústria e demissão dos funcionários, considerando o cenário atual, a dificuldade de recolocação dos trabalhadores demitidos e as demais implicações sociais que esta medida causaria caso fosse adotada.

\section{Empreendedorismo}

A questão 4 desafia o aluno a refletir sobre questões relacionadas a busca de oportunidades (como por exemplo a fabricação de peças em chumbo derretido), empreendedorismo (criação da empresa) e inovação (busca novos produtos, uso de tecnologia de ponta) aplicadas pelos fundadores da empresa nos quarenta anos de existência da metalúrgica. Mesmo considerando que a empresa se ajustou ao ambiente ao longo de sua história, tanto por tentativas, erros e acertos, quanto pela aplicação de conceitos teóricos adquiridos no curso de Administração por Irineu, percebe-se claramente a evolução da empresa, pois começou de praticamente nada, no quintal de casa, até atingir a condição atual com a nova indústria, atendendo a diversos mercados nacionais e internacionais. Com base na história e no crescimento da empresa, pode-se perceber o comportamento empreendedor dos envolvidos.

O conceito de empreendedorismo, popularizado no Brasil a partir da década de 1990, tem desencadeado vários estudos no sentido de entender quem é de fato empreendedor, com dilemas do tipo "o empreendedor nasce pronto, ou pode aprender a ser empreendedor durante a vida?". Para Dolabella (1999, p. 12), é possível aprender a ser empreendedor, desde que haja motivação para tal, nesse sentido estabelece que para que um indivíduo se torne de fato um empreendedor, deverá "aprender a pensar e agir por conta própria, com criatividade, liderança e visão de futuro, para inovar e ocupar o seu espaço no mercado, transformando esse ato também em prazer e emoção".

Para Filon (1999), a atividade empreendedora requer a aplicação de conceitos chaves como visão, energia, liderança e relações interpessoais. A visão no sentido de prospectar novos horizontes pessoais e organizacionais, e acima de tudo acreditar na possibilidade de sucesso; a energia para enfrentar as dificuldades tanto físicas quanto mentais inerentes a qualquer desafio organizacional; a liderança para saber conduzir a equipe aos resultados desejados de forma que todos estejam motivados e saibam os caminhos que precisam trilhar; e, as relações interpessoais para que barreiras sejam vencidas através dos contatos que precisam ser realizados diariamente nos ambientes interno e externo.

\section{Competição Global}

O Comércio Internacional propagou-se na mesma velocidade em que os canais de comunicação foram sendo desenvolvidos, sobretudo pelo aperfeiçoamento da internet. Esse tipo de comércio é caracterizado pela importação e exportação de produtos e serviços entre países, entre pessoas e empresas de diferentes países (ASSUMPÇÃO, 2007). A competição acirrada entre as organizações tem exigido esforços constantes dos gestores acerca das novas formas de atuação nos mercados localizados em diversas partes do mundo. Ficou no passado a idéia que a concorrência era restrita apenas a competidores regionais ou locais.

Hoje, com a expansão dos canais de comunicação, que possibilitou a globalização e maior agilidade nos negócios, é possível comprar praticamente tudo o que o consumidor precisa, mesmo a milhares de quilômetros, não obedecendo mais aos limites geográficos para essas compras. Diversas vezes estas compras ocorrem para compensar o consumidor em relação a: disponibilidade, variedade, qualidade, quantidade e preço, não encontrados nos produtos locais. Nesse ponto ressalta-se o nível da competição entre as empresas, ou seja, não é porque o ofertante de determinado produto esteja fisicamente próximo do consumidor, que este dará preferência para 
compra, na maioria das vezes, preferindo aquele que lhe trouxer mais benefícios.

Assim, as questões 5 e 6 foram propostas para que os alunos reflitam sobre esse fenômeno mercadológico e possam entender até que ponto as importações são oportunidades para expansão da empresa ou se representam algum tipo de ameaça a sobrevivência e manutenção da Spinbras como fabricante e distribuidora de peças. O Professor poderá indagar se os discentes já realizaram compras ou se conhecem pessoas ou empresas que compram produtos oriundos da China, buscando exemplificar mais o caso e trabalhar com a realidade.

\section{Desfecho do Caso}

Irineu chegou entusiasmado à sala do seu irmão para dizer-lhe o que decidiu com base em todos os dados que possuía. Henrique, ao ouvir seu irmão Irineu dizendo o que exatamente iria acontecer, aconchegouse em sua cadeira e atentamente ouviu de Irineu que a melhor forma para esse caso, seria continuar a produção e manter a empresa no mercado como fizeram nos últimos quarenta anos. Irineu argumentou que pelos conhecimentos que possui, não acredita que na China os produtos continuem muito competitivos nos próximos anos. Uma das causas, segundo Irineu, é a oferta de mão de obra que já começa a dar sinais de escassez, e como isso tem seu valor aumentado. "Iá se vê muitos empregados trocando de empresas por salários maiores. Também se vê empresários oferecendo maiores salários para atrair trabalhadores".

Outras duas razões determinaram a tomada de decisão de Irineu, a primeira, sua empresa já está consolidada e simplesmente sair do mercado e jogar fora tudo o que foi conquistado até hoje, não lhe pareceu o mais correto. Como os clientes reagiriam? O que os próprios empresários iriam fazer da vida? $\mathrm{O}$ que falariam para seus filhos que já estão atuando na empresa, inclusive um dos filhos de Irineu que cursou engenharia mecânica justamente para trabalhar na empresa da família. A segunda razão consiste na manutenção daquilo que chamam de "maior patrimônio", a força dos seus funcionários, alguns já aposentados e outros próximos disso. "Não se pode pensar somente em si e deixar muitas familias desamparadas. Eu nem teria prazer em gastar o dinheiro que ganhasse a mais", argumenta Irineu.

Irineu tomou a decisão com muita convicção e confiança no futuro. A principal ameaça consiste na possibilidade de seus clientes comprarem os produtos diretamente da China, pagando num primeiro momento um preço menor. Se isso realmente ocorrer, Irineu acredita que nem todos os clientes tomarão esse rumo, tendo em vista a distancia para negociações e as dificuldades culturais que permeiam a negociação. Mas, ainda que esse processo ocorresse em larga escala, a empresa ainda tem o capital humano, intelectual e tecnológico, podendo até mudar de linhas de produtos, se for o caso.

Para aproveitar os conhecimentos que adquiriu, Irineu fundou uma nova empresa, a Spinbras, no ramo de importação. Produtos das áreas de jardinagem e trabalhos no campo são importados da China e de outros países, recebem a marca no Brasil, e já estão sendo comercializados em diversos estados brasileiros.

\section{Referências}

ANSOFF, H. Igor. Do planejamento estratégico à administração estratégica. São Paulo : Atlas, 1990.

ANSOFF, H. Igor. Implantando a administração estratégica. São Paulo : Atlas, 1993.

ASSUMPÇÃO, Rossandra Mara. Exportação e Importação: conceitos e procedimentos básicos. Curitiba: Ibpex, 2007.

CÂMARA de Comércio Brasil China. Noticias sobre negócios com a China. Disponível em: http://www.camarabrasilchina.com.br/noticias-epublicacoes/noticias/noticias-sobre-negocios-com-achina/. Acesso em 30 jun. 2015

DOLABELA, Fernando. O segredo de Luísa. São Paulo: Cultura Editores Associados, 1999.

DORNELAS, José Carlos Assis.

Empreendedorismo: transformando idéias em negócios. Rio de Janeiro: Elsevier, 2001.

FERNANDES, Daniela. Desemprego aumentará até 2016, diz OIT. BBC BRASIL. Disponível em: http://www.bbc.com/portuguese/ noticias/2015/01/150119_taxa_desemprego_df_rb. Acesso em 30 jun. 2015

FILION, Luis Jacques. Empreendedorismo: empreendedores e proprietários de pequenos negócios. RAUSP - Revista da Administração, 
São Paulo, v.34, n.2, abr.-jun. 1999.

JORNAL O POVO - Passo a Passo para importar. Reportagem: Ingrid Coelho. 28/04/2014.

Disponível em: https://www20.opovo.com. br/app/opovo/economia/2014/04/28/ noticiasjornaleconomia,3242475/passo-a-passo-paraimportar.shtml > Visitado em 05/10/2025.

KOTLER, Philip; KELLER, Kevin Lane. Administração de Marketing. 12. ed. São Paulo: Pearson Prentice Hall, 2006. 776 p.

MCCREADIE, Karen. A Arte da Guerra SUN

TZU: uma interpretação em 52 ideias brilhantes: 1. ed. São Paulo: Globo, 2008.

MINTZBERG, H.; QUINN, J. B.. O processo de estratégia. 3 ed. Porto Alegre: Bookman, 2001

PARAGUAÇU, Lisandra; BORGES, André. Brasil e China assinam 35 acordos em visita do premie ao país. Jornal o Estado de São Paulo, Edição do dia 19/05/2015. Disponível em: http:/ / economia. estadao.com.br/noticias/geral,brasil-e-china-assinam35-acordos-em-visita-do-premie-ao-pais, 1690267. Acesso em: 25 mai. 2015

PORTER, Michael Eugene. A Vantagem

Competitiva das Nações. 5a ed. Rio de Janeiro: Campus, 1998.

OLIVEIRA, Djalma Pinho Rebouças.

Planejamento Estratégico. $23^{a}$ ed. São Paulo: Atlas, 2007.

O ESTADO DE SÃO PAULO - Jornal. Brasil lidera ranking de encargos trabalhistas.

Reportagem: Guilherme Waltenberg, da Agência Estado, 22 Fevereiro 2013 | 19h17. Disponível em: https://economia.estadao.com.br/ noticias/geral,brasil-lidera-ranking-de-encargostrabalhistas,144916e > Visitado em: 20/09/2015

SERTEK, Paulo. Responsabilidade Social e Competência Interpessoal. Curitiba: Ibpex, 2006.

SILVEIRA, D.; CAVALLINI, M. - Desemprego fica em 13,7\% no $1^{\circ}$ trimestre de 2017 e atinge 14,2 milhões. Portal G1, reportagem do dia 28/04/2017. Disponível em: https://g1.globo.com/ economia/noticia/desemprego-fica-em-137-no-1trimestre-de-2017.ghtml . Visitado em 10/11/2017.

TACHIZAWUA, Takeshy. Gestão Ambiental e Responsabilidade Social Corporativa. São Paulo:
Atlas, 2008.

TENÓRIO, Fernando Guilherme (organizador); colaboradores Fabiano Christian Pucci do Nascimento... (et al.). Responsabilidade Social Empresarial. - $2^{\mathrm{a}}$ ed. rev. e ampl. - Rio de Janeiro: Editora FGV, 2006. (Coleção FGV Prática).

WRIGHT, Peter L.; KROLL, J. Mark, PARNELL, John. Administração Estratégica: conceitos. Tradução Celso A. Rimoli, Lenita R. Esteves. São Paulo: Atlas, 2000. 